\title{
Résistance et espoir : leçons en temps de guerre
}

\section{Guilherme Ribeiro}

\section{(2) OpenEdition}

\section{Journals}

\section{Édition électronique}

URL : https://journals.openedition.org/espacoeconomia/19750

DOI : 10.4000/espacoeconomia.19750

ISSN : 2317-7837

\section{Éditeur}

Núcleo de Pesquisa Espaço \& Economia

\section{Référence électronique}

Guilherme Ribeiro, «Résistance et espoir : leçons en temps de guerre », Espaço e Economia [En ligne] 21 | 2021, mis en ligne le 15 juillet 2021, consulté le 17 juillet 2021. URL : http://

journals.openedition.org/espacoeconomia/19750; DOI : https://doi.org/10.4000/espacoeconomia. 19750

Ce document a été généré automatiquement le 17 juillet 2021.

\section{c) (†) (2)}

Espaço e Economia - Revista brasileira de geografia econômica est mise à disposition selon les termes de la licence Creative Commons Attribution - Pas d'Utilisation Commerciale - Partage dans les Mêmes Conditions 4.0 International. 


\title{
Résistance et espoir : leçons en temps de guerre
}

\author{
Guilherme Ribeiro
}

1 Temps indescriptibles, mais pas inexplicables. Appuyés sur presque soixante millions de patriotes, Bolsonaro et le Bolsonarisme sont la nouvelle expression de ce qu'il y a de plus vieux dans la société brésilienne : l'autoritarisme et le génocide, la violence et la déforestation, le racisme et la discrimination. Né dans un des milieux le plus infâme de la vie nationale, le militarisme, Jair Messias Bolsonaro a réussi à entrer dans l'histoire exactement comme il le voulait. Au moment où l'on écrit cet éditorial (le 14 juillet 2021), le Brésil atteint le cap de plus de cinq cent mille morts à cause de la Covid-19. Même dans un pays habitué à plusieurs crises, les viscères de la société brésilienne sont aussi exposés que célébrés. En réunissant des groupes tels que les média, les banques, l'agrobusiness, les parti politiques, les églises évangéliques et des fractions de la justice, le projet néocolonial et néolibéral de la bourgeoisie dans la périphérie capitaliste montre ses contradictions sans aucun type de pudeur, faute, repentance. Bien au contraire, le ton de la marche, c'est la moquerie, la dérision, la zizanie. La tragédie de l'accroissement de la pauvrété et de la misère dans les grandes villes brésiliennes contraste avec l'augmentation des revenus des plus riches. Dans ce cas, qu'est-ce qu'on peut dire de l'immobilité et du silence des banques - les plus entrepreneurs des entrepreneurs, les plus compétents des compétents, les plus aptes parmi les aptes dans un des moments les plus critiques de l'histoire?

2 Temps indicibles, mais pas impassibles. Résistance contre le nazi-fascisme et toutes ses modulations, notre éditorial veut faire entendre les voix dissonantes et soutenir haut et fort que l'histoire brésilienne n'aura pas ni présent, ni futur jusqu'à ce qu'elle reconnaisse, problématise et dépasse sa généalogie esclavagiste, autoritaire et élitiste. De Canudos à Marielle Franco, de la dictature militaire aux milices à Rio, nous avons une nation incapable de s'ériger en tant qu'une société fondée sur l'espace public, l'universalité de la santé et de l'instruction, le droit à la vie et à la ville. En tournant le dos à la chose publique en générale, le résultat est la scandaleuse concentration du gain et de la terre, la perpétuation braudélienne du népotisme, l'expansion l'économie 
informelle, l'étouffement de la mobilité sociale, la naturalisation de la violence policière étatique, l'émergence des milices, l'hypocrisie de la guerre contre le trafic des drogues, le négationnisme revêtu d'une sorte de mysticisme pré-moderne, la discrimination contre les minorités au nom de la famille et des enfants, la chosification du corps féminin noir... Tous ces éléments ne sont pas cependant exceptionnels, isolés ou circonstanciels. Ils sont soudés dans un grand réseau dont les uns expliquent les autres. De plus, nos meilleurs intellectuels (tels que Josué de Castro, Lélia Gonzalez, Milton Santos, Francisco de Oliveira, Sueli Carneiro et Jessé de Souza) nous enseignent que l'étude des contradictions sociales n'admet pas des formules dichotomiques, simplificatrices, déterministes.

3 Temps inexprimables, mais pas indolents. A la fin, le pays responsable de fêter la dictature militaire et de renouveler ses spectres cinquante ans après est le même capable de créer un chef d'œuvre tel que le roman Torto Arado exactement à l'aube du Bolsonarisme. Une masterpiece de la littérature mais aussi de la pensée sociale lato sensu, la pleine reconnaissance de Torto Arado ne sera atteinte que lorsque le peuple brésilien est capable de le lire et le discuter en place publique, dans les écoles, pendant les repas. Publié en 2019, comment cacher notre fierté devant le fait qu'Itamar Vieira Junior est géographe et fonctionnaire publique de l'Institut Nationale de Colonisation et de la Réforme Agraire? Dans son roman, les femmes protagonistes descendantes des esclaves Bibiana et Belonísia symbolisent tout ce qui nous opprime durant les derniers cinq siècles. C'est curieux de constater que Vieira Junior est né à Bahia, précisément le lieu où les Portugais ont débarqué au XVème siècle pour commencer la conquête, le géenocide, la violence. Géographe de formation avec un master en géographie et un doctorat en études ethniques et africains, sa littérature conçoit une atmosphère où les lieux, les territoires, les corps, la nature et la culture révèlent l'impact des inégalités de la formation socio-spatiale brésilienne sur les quilombolas, les noirs, les migrants, les sans-terre, les paysans et les femmes. Ainsi, dans le processus de décolonisation du curriculum géographique maintenant en cours en différentes parties du monde, Torto Arado est dorénavant une référence primordiale (Vieira Junior 2019).

$4 \mathrm{Au}$ nom de tous les éditeurs et de tous ceux qui contribuent avec Espaço e Economia: Revista Brasileira de Geografia Econômica, c'est avec émotion que nous dédions cette édition à la mémoire de la géographe Neli Aparecida de Mello-Théry (EACH/USP), décédée au mois d'avril 2021 d'un cancer. Intellectuelle engagée sur la question environnementale, professeure généreuse et accueillante, ouvrière infatigable, en pratiquant la coopération et la collectivité au détriment de la compétition et de l'individualisme, Neli nous laisse comme héritage le projet d'une université et d'une société démocratiques, transparentes et horizontales. Enthousiaste d'Espaço e Economia dès le début à côté de son mari Hervé Théry (la Confins a toujours été un modèle pour nous), nous avons eu la chance de publier des articles de Neli tels que Mapeamento do trabalho escravo contemporâneo no Brasil : dinâmicas recentes (Girardi, Mello-Théry, Théry et Hato 2014) - l'article le plus consulté de notre revue - et A geopolítica do Covid-19 (Mello-Théry et Théry 2020). Maintenant nous sommes fier de publier Iniciativas para mitigação das ilhas de calor em cidades médias: o caso de Jacareí-São Paulo (Mello-Théry, Cavicchioli et Caldas 2021).

Que les valeurs éthiques cultivées par Neli soient toujours avec nous. 


\section{BIBLIOGRAPHIE}

Carneiro, S. (2019). Escritos de uma vida. São Paulo: Jandaíra. 296p.

de Castro, J. (1946). Geografia da fome. Rio de Janeiro: O Cruzeiro. 354p.

de Oliveira, F. (2003). Crítica à razão dualista/O ornitorrinco. Campinas: Boitempo. 150p.

de Souza, J. (2017). A elite do atraso. Da escravidão à Lava-Jato. São Paulo: Leya. 240p.

Girardi, E.P., Mello-Théry, N.A. de, Théry, H., Hato, J. (2014). Mapeamento do trabalho escravo contemporâneo no Brasil : dinâmicas recentes. Espaço e Economia [Online], 4. URL: http:// journals.openedition.org/espacoeconomia/804

Gonzalez, L. (1981 [1980]). Racismo e sexismo na cultura brasileira. In: Kemper, A.K. (coord.). Psicanálise e política. Rio de Janeiro: Editora Clínica Social de Psicanálise, 155-180.

Mello-Théry, N.A. de, Théry, H. (2020). A geopolítica do Covid-19. Espaço e Economia [Online]. Edição Especial: Dossiê Coronavírus. Parte I, 17. URL: http://journals.openedition.org/espacoeconomia/ 11224

Santos, M. (1979). O espaço dividido: os dois circuitos da economia urbana dos países subdesenvolvidos. Rio de Janeiro: Francisco Alves. 345p.

Vieira Junior, I. (2019). Torto Arado. São Paulo: Todavia. 264p.

\section{AUTEUR}

\section{GUILHERME RIBEIRO}

Departamento de Geografia, Programa de Pós-Graduação em Geografia, Laboratório Política, Epistemologia e História da Geografia, Universidade Federal Rural do Rio de Janeiro. Email: lapehge@gmail.com 